\section{Decisão de compra e comportamento dos consumidores de serviços de reparos automotivos}

\author{
Daniel Barbosa Cabral \\ Carlos André Corrêa Mattos ${ }^{2}$ \\ Mayara Pereira Monteiro ${ }^{3}$ \\ Renê Alves Silva ${ }^{4}$
}

\begin{abstract}
Resumo
Este artigo tem o objetivo de identificar os fatores que influenciam a decisão de compra e o comportamento do consumidor de serviços de reparos automotivos. A pesquisa quantitativa é classificada como exploratória e descritiva. Utilizou-se um questionário estruturado para coletar dados, com perguntas afirmativas e de múltiplas escolhas para a identificação do perfil dos entrevistados e variáveis relacionadas ao comportamento do consumidor e decisão de compra. Foram entrevistados 178 proprietários de automóveis que residem na cidade de Parauapebas-PA. Os dados foram analisados com técnicas de estatística descritiva e análise multivariada. Os resultados demonstraram que os consumidores de serviços de reparos automotivos são influenciados por três fatores: (1) imagem da oficina; (2) confiança na oficina; e (3) serviços e peças com garantia. Por fim, conclui-se que as oficinas devem implementar ações para atender as necessidades e expectativas dos consumidores, visando obter a escolha na decisão de compra.
\end{abstract}

Palavras-chave: Decisão de compra. comportamento do consumidor. oficinas mecânicas. setor automotivo.

\begin{abstract}
This article aims to identify the factors that influence the purchase decision and the consumer behavior of automotive repair services. Quantitative research is classified as exploratory and descriptive. A structured questionnaire was used to collect data, with affirmative and multiple-choice questions to identify the interviewees' profile and variables related to consumer behavior and purchase decision. 178 car owners who live in the city of Parauapebas-PA were interviewed. The data were analyzed using techniques of descriptive statistics and multivariate analysis. The results showed that consumers of automotive repair services are influenced by three factors: (1) image of the workshop; (2) confidence in the workshop; and (3) services and parts with warranty. Finally, it is concluded that the workshops must implement actions to meet the needs and expectations of consumers to obtain the choice in the purchase decision.
\end{abstract}

Keywords: Purchase decision. consumers behavior. machine shop. automotive sector.

${ }^{1}$ Doutorando em Gestão de Empresas pela Universidade de Coimbra, Mestre em Administração pela Universidade da Amazônia, Especialista em Finanças Empresariais pela Universidade Federal da Bahia e Bacharel em Administração. Professor Assistente de Gestão Empresarial da Universidade Federal Rural da Amazônia. E-mail: danicabral@msn.com

${ }^{2}$ Doutor em Ciências Agrárias pela Universidade Federal Rural da Amazônia (UFRA), Mestre em Gestão e

Desenvolvimento Regional pela Universidade de Taubaté (Unitau). Cursou MBA em Gestão Empresarial e Gerenciamento de Projetos pela Fundação Getúlio Vargas (FGV). Bacharel em Administração pela Universidade da Amazônia (Unama). E-mail: carlosacmattos@gmail.com

${ }^{3}$ Bacharel em Administração pela Universidade Federal Rural da Amazônia (UFRA).E-mail: mayarapmc@hotmail.com

${ }^{4}$ Bacharel em Administração pela Universidade Federal Rural da Amazônia (UFRA). E-mail: renealvinha@gmail.com

Artigo recebido em: 26 de novembro de 2019. Artigo aceito em 11 de janeiro de 2021. 


\section{Introdução}

A indústria automobilística tem enorme relevância na economia mundial. Estima-se que movimente cerca de US\$ 2,5 trilhões por ano e por causa desses valores e de seu forte efeito multiplicativo na cadeia produtiva, atribui-se a ela $10 \%$ do PIB dos países desenvolvidos (CASOTTI; GOLDENSTEIN, 2008). Com mais de 50 anos de indústria automotiva, o Brasil apresenta um grande mercado doméstico efetivo e potencial, competente parque produtor, tanto de veículos quanto de sistemas e autopeças, sólida base de engenharia automotiva e rede de concessionários estruturada com abrangência nacional (CASOTTI; GOLDENSTEIN, 2008). O cenário brasileiro torna-se favorável, aumentando assim, a competição entre os prestadores de serviços.

O consumidor de serviços automotivos pode contratar os reparos do seu veículo em concessionárias oficiais das próprias marcas ou em oficinas mecânicas multimarcas. Esse mercado tende a crescer em participação relativa, devido a redução da demanda por veículos novos no ano de 2015 e o menor dinamismo econômico previsto para os próximos anos (BARROS; CASTRO; VAZ, 2018).

O maior tempo de uso dos veículos pode levar ao aumento do consumo de serviços de reparos automotivos, visto que quanto maior for o tempo de uso dos veículos, maior é a necessidade de manutenções preventivas e corretivas para ele continuar a funcionar bem. Os empresários e gestores de oficinas que prestam serviços de reparo automotivo são obrigados a buscarem alternativas gerenciais que possam agregar valor ao serviço a fim de atrair novos clientes e manter os atuais (KOROCOSKI; FERREIRA; ATMANCUZK, 2016).

A idade média da frota de veículos no Brasil atingiu nove anos e sete meses, sendo que no período entre 2012 a 2017, a idade média dos veículos em circulação subiu cerca de um ano (SINDIPEÇAS, 2018). Diante do cenário de crescimento do setor de serviços de reparos automotivos, consequentemente, do aumento da competitividade entre as empresas e da importância de conhecer o comportamento do consumidor, torna-se relevante identificar o perfil de consumo e comportamento dos clientes na decisão de compra de serviços automotivos.

As empresas estão adotando várias práticas comerciais, desde a oferta de preços baixos, serviços gratuitos e prazos cada vez mais flexíveis, até a diferenciação por meio 
de um ambiente agradável (instalações), tecnologia de ponta (equipamentos modernos) e atendimento diferenciado proporcionado pelo pessoal de linha de frente, de modo a conquistar e reter clientes, uma vez que os consumidores tem cada vez menos tempo disponível, estão exigindo mais qualidade, agilidade e serviços de qualidade (OLIVEIRA et al., 2014; SANEMATSU; SILVA; VIEIRA, 2016).

Nesse contexto, o objetivo deste artigo é identificar os fatores que influenciam a decisão de compra e no comportamento do consumidor de serviços automotivos. Além disso, pretende-se investigar as preferências dos consumidores entre as oficinas credenciadas pelas montadoras e as oficinas multimarcas e apresentar algumas das suas características para tomada de decisão de compra. Para alcançar os resultados, foram entrevistados 178 consumidores no munícipio de Parauapebas, estado do Pará. Os dados foram analisados com técnicas de estatística descritiva e análise multivariada (análise fatorial exploratória).

\section{REVISÃO DE LITERATURA}

\subsection{DECISÃO DE COMPRA}

A decisão de compra é parte fundamental do comportamento do consumidor, mas as formas como as pessoas avaliam e optam por produtos variam muito, dependendo de dimensões como o grau de novidade ou risco relacionado à decisão (SOLOMON, 2016).

Este trabalho apresenta um modelo de cinco etapas baseados em Kotler e Keller (2012) e Solomon (2016). O processo de compra é representado pela Figura 1 e inclui os seguintes estágios: reconhecimento da necessidade, busca de informações, avaliação de alternativas, decisão de compra e comportamento pós-compra. Todas essas etapas nem sempre são seguidas para a realização de uma compra, visto que o consumidor pode pular ou inverter algumas delas (KOTLER; KELLER, 2012). 


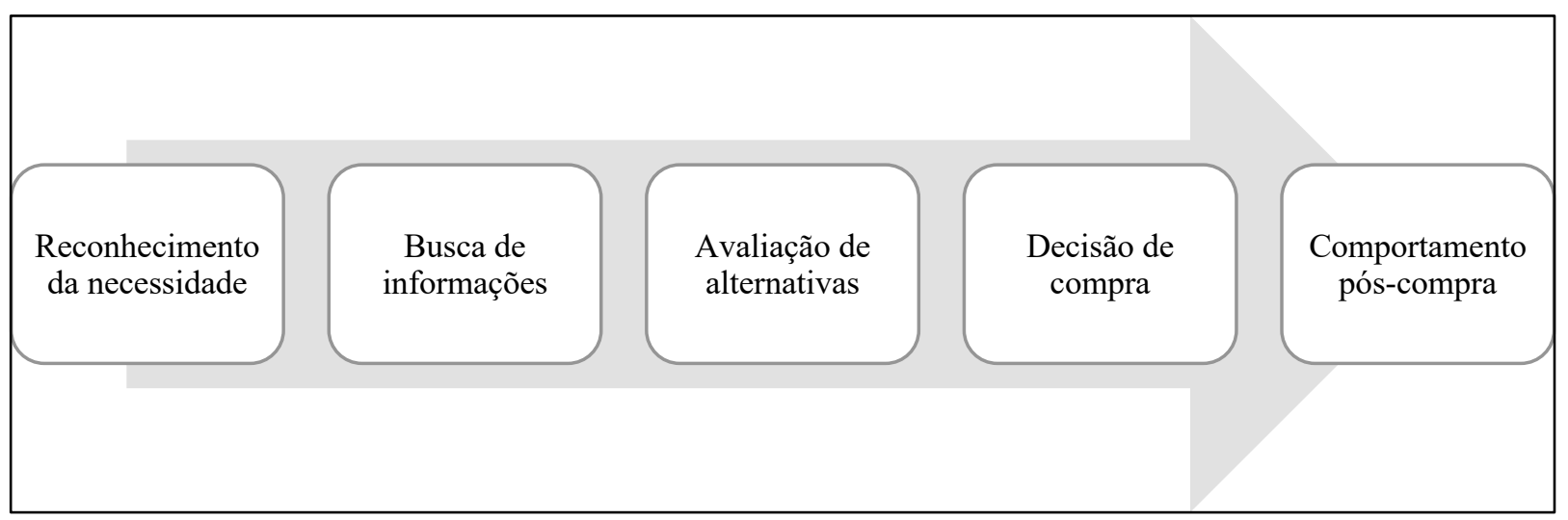

Figura 1: Processo de compra

Fonte: Adaptado de Kotler e Keller (2012) e Solomon (2016).

O processo de compra de produtos e serviços começa com a identificação de um problema, isto é, com o reconhecimento de uma necessidade do consumidor (CHURCHILL; PETER, 2012). Essa necessidade pode ser impulsionada por estímulos internos, como fome e sede, que surgem como nível de consciência, e de estímulos externos, que é despertado a partir da influência do meio social, como as propagandas (PANDO; PANDO, 2013).

As necessidades podem ser claramente definidas, como a necessidade de fazer uma refeição, ou não tão fáceis de serem satisfeitas ou articuladas, como a vontade de tirar férias, por isso qualquer que seja a natureza da compra em potencial, estas podem ser relativamente simples ou bastante complexas e até abstratas, como as necessidades psicogênicas (CHISNALL, 1995).

O consumidor, após reconhecer a necessidade, sempre está inclinado a buscar mais informações antes de se decidir pela compra de determinado produto que irá satisfazer as suas necessidades não atendidas (PANDO; PANDO, 2013). A busca de informações é o processo pelo qual o consumidor pesquisa o ambiente à procura de dados para tomar uma decisão razoável (SOLOMON, 2016).

A busca pode ser interna, recuperando o conhecimento (memória), ou externa, coletando informações de familiares e no mercado (RANI, 2014). As principais fontes de informações procuradas pelos consumidores, segundo Churchill e Peter (2012) são apresentadas no quadro 1, a seguir: 
Quadro 1 - Fontes de informação para decisão de compra

\begin{tabular}{|l|l|}
\hline \multicolumn{1}{|c|}{ Fontes } & \multicolumn{1}{c|}{ Descrição } \\
\hline Internas & $\begin{array}{l}\text { Informações armazenadas na memória da pessoa, podendo ser a única utilizada pelo } \\
\text { consumidor na hora de realizar compras rotineiras. }\end{array}$ \\
\hline Grupos & $\begin{array}{l}\text { Informações coletadas com amigos, familiares e outras pessoas. Pode ser uma das mais } \\
\text { poderosas maneiras de influência de compra por sua alta confiabilidade e credibilidade. }\end{array}$ \\
\hline Marketing & $\begin{array}{l}\text { Informações contidas nas ações de marketing, por meio de propaganda, embalagens e } \\
\text { outros aspectos. São as mais acessíveis aos consumidores, porém, nem sempre são as } \\
\text { mais confiáveis. }\end{array}$ \\
\hline Públicas & $\begin{array}{l}\text { Informações encontrados em artigos feitos por pesquisadores ou organizações } \\
\text { independentes possuem alto grau de confiabilidade, mas são mais difíceis de serem } \\
\text { obtidas pelos consumidores. }\end{array}$ \\
\hline Experimentação & $\begin{array}{l}\text { Informações obtidas por meio da experimentação dos produtos, sendo geralmente a } \\
\text { última fonte usada antes da compra, pela exigência do consumidor ter o produto } \\
\text { disponível. }\end{array}$ \\
\hline
\end{tabular}

Fonte: Adaptado de Churchill e Peter (2012).

De acordo com Churchill e Peter (2012), é a partir dessas fontes de informações que os consumidores conhecem as várias alternativas de um produto satisfazer suas necessidades. Sendo que cada fonte de informação desempenha uma função diferente ao influenciar a decisão de compra do consumidor, variando conforme a categoria de produtos e as características do comprador (KOTLER; KELLER, 2012).

A avaliação de alternativas pode ser conceituada como o processo pelo qual uma alternativa de escolha é analisada e selecionada para atender às necessidades do consumidor. Ocorre simultaneamente com o processo de busca de informações, pois os consumidores aceitam, discutem, distorcem ou rejeitam as informações que chegam à medida que as recebem (CHURCHILL; PETER, 2012).

Durante este estágio, o consumidor tem necessidade de estabelecer critérios para avaliação, características que ele quer ou não quer no produto (RANI, 2014). Por meio desse processo de avaliação de alternativas, os consumidores tentam identificar a compra que lhes trará o maior valor, e assim, eles avaliam os benefícios que consideram mais importantes em relação aos custos esperados da transação (CHURCHILL; PETER, 2012).

Para Cobra (2015), a influência da marca é significativa na avaliação de alternativas, visto que entre várias marcas do mesmo produto prevalece aquela mais reconhecida e lembrada no mercado, bem como a alternativa de solução mais rápida 
reflete quando o fator tempo é preponderante, e o produto com melhor alternativa de custo quando o fator preço for importante. $\mathrm{Na}$ fase de decisão de compra, o consumidor cria preferências entre as marcas do conjunto de escolha e forma uma intenção de comprar as preferidas (KOTLER; KELLER, 2012).

As decisões de compra são constituídas por diversas decisões menores que podem envolver atributos e aspectos específicos de um produto, como preço, método de pagamento, quantidade, marca favorecida e local de compra, sendo que essas decisões separadas demandam avaliações individuais antes de se chegar à decisão final de comprar um produto específico (CHISNALL, 1994).

Churchill e Peter (2012) classificam três tipos de tomada de decisão, onde o modo como comprar depende em parte da importância da compra. 1) tomada de decisão rotineira envolve poucas atividades de pesquisa e ocorre normalmente na compra de produtos simples, baratos e conhecidos; 2) decisão limitada exige um nível moderado de pesquisa e compra, onde os consumidores consideram várias marcas e lojas; e 3) decisão extensiva geralmente é utilizada na compra de produtos caros, poucos conhecidos ou complexos, por isso envolve a comparação de muitas alternativas.

O processo de decisão do consumidor não termina com a compra, visto que a experiência de aquisição e uso fornece elementos que serão utilizados no futuro, consequentemente, o consumidor mostrará satisfação ou insatisfação em relação ao produto comprado (COBRA, 2015).

Quando os benefícios são maiores que os custos, valor alto é percebido e o consumidor fica satisfeito, entretanto, se os benefícios forem menores do que os custos, o consumidor pode concluir que recebeu um valor baixo e ficar insatisfeito com a aquisição (CHURCHILL; PETER, 2012).

Quanto maior a diferença entre as expectativas em relação ao produto e o seu desempenho, maior será a insatisfação do consumidor. Se o desempenho não atender inteiramente as expectativas, o cliente fica desapontado, se atender às expectativas, $o$ consumidor fica satisfeito e encantado quando as expectativas são superadas (KOTLER; KELLER, 2012).

\subsection{COMPORTAMENTO DO CONSUMIDOR}

A administração de marketing é responsável por estudar o comportamento de 
compra do consumidor. Os responsáveis pela área de marketing poderiam ter compreensão de como os consumidores pensam, agem e sentem para oferecer um valor adequado a cada consumidor-alvo, isto é, entender por que, o que, de que maneira e onde compram (KOTLER; KELLER, 2012).

O comportamento do consumidor é um processo contínuo e não se restringe somente ao momento da compra (SOLOMON, 2016). É o estudo dos processos compreendidos quando indivíduos, grupos ou organizações escolhem, compram, utilizam ou descartam produtos, serviços, ideias ou experiências para satisfazerem necessidades e desejos (KOTLER; KELLER, 2012; SOLOMON, 2016).

A necessidade é algo indispensável e são requisitos para a sobrevivência (CHURCHILL; PETER, 2012). Por exemplo, todas as pessoas necessitam de alimentação, vestuário, habitação e outros itens. Desejo é um estado psicológico direcionado a uma aspiração, sem que seja preciso haver uma ausência que justifique o sentimento e a ação decorrentes (LIMEIRA, 2008). Assim, as necessidades tornam-se desejos quando direcionadas à objetos específicos (COBRA, 2015).

O comportamento do consumidor também é compreendido como um conjunto de reações dos indivíduos a determinados estímulos, que provêm de fatores pessoais, ambientais situacionais e de marketing (LIMEIRA, 2008). Outra definição de comportamento do consumidor, aponta como sendo atividades mentais, físicas e sociais que resultam em decisões e ações de pagar, comprar e usar produtos/serviços, assim como descartá-los (SETH; MITTAL; NEWMAN, 2001)

Com essas acepções fica claro que o comportamento do consumidor apresenta várias características: ele é motivado, é um processo, inclui várias atividades, envolve diferentes papéis, é influenciado por fatores internos e externos, difere entre as pessoas e é complexo (LARENTIS, 2012). Por isso, para entender o comportamento do consumidor, diversas áreas do conhecimento científico são envolvidas, como antropologia, sociologia, psicologia entre outras (COBRA, 2015).

Existem múltiplos fatores que agem como influenciadores do comportamento de compra do consumidor (COBRA, 2015). O quadro 2 apresenta alguns destes fatores pesquisados.

Quadro 2 - Características dos Fatores de Influência no Comportamento do Consumidor

Revista Eletrônica Gestão e Serviços v.11, n. 2, pp. 3240 - 3260, Julho/Dezembro 2020. ISSN Online: 2177-7284 e-mail: regs@metodista.br 


\begin{tabular}{|c|c|c|}
\hline Fatores & Características & Autores \\
\hline Culturais & $\begin{array}{l}\text { As influências culturais exercem um papel de grande } \\
\text { importância no comportamento do consumidor Sendo } \\
\text { considerada um dos fatores que desempenham a mais } \\
\text { ampla e profunda influência sobre os consumidores. }\end{array}$ & $\begin{array}{c}\text { Medeiros e Cruz (2006) e } \\
\text { Kotler e Keller (2012) }\end{array}$ \\
\hline Sociais & $\begin{array}{l}\text { Os fatores sociais são as influências exercidas sob o } \\
\text { indivíduo pelas classes sociais. Alguns critérios são } \\
\text { utilizados como indicadores, como a profissão e o poder } \\
\text { aquisitivo, além de variáveis correspondentes aos valores } \\
\text { pessoais, aos grupos de influências, como família e amigos, } \\
\text { e ao estilo de vida }\end{array}$ & Oliveira et al. (2014) \\
\hline Pessoais & $\begin{array}{l}\text { As características pessoais como idade, ocupação, } \\
\text { circunstâncias econômicas, estilo de vida, estágio do ciclo } \\
\text { de vida, personalidade e autoimagem também influenciam } \\
\text { na decisão de compra }\end{array}$ & $\begin{array}{c}\text { Medeiros e Cruz (2006) e } \\
\text { Oliveira et al. (2014) }\end{array}$ \\
\hline Psicológicas & $\begin{array}{l}\text { As influências psicológicas têm relação com o interior do } \\
\text { indivíduo. Os estudos psicológicos têm cada vez mais } \\
\text { importância para os profissionais que buscam entender o } \\
\text { comportamento do consumidor, uma vez que trazem uma } \\
\text { dimensão muito profunda de influências intrapessoais }\end{array}$ & Kotler e Keller (2012) \\
\hline
\end{tabular}

\section{Fonte: Elaborado pelos autores.}

\subsection{QUALIDADE E FIDELIZAÇÃO EM SERVIÇOS DE REPAROS AUTOMOTIVOS}

As características de compras de serviços de reparos automotivos podem ser sensíveis ao consumidor. Reparos e manutenções automotivas são partes importantes dos serviços pós-venda da indústria automobilística, determinam diretamente a satisfação e a lealdade dos clientes, e a oficina mecânica é o principal portador deste processo (TAN, YU e YIN, 2009). Os consumidores estão mais conscientes da qualidade do que nunca e em nenhum lugar isso é mais aparente do que na indústria automotiva (DEVARAJ; MATTA; CONLON, 2001).

A qualidade dos serviços pode influenciar na fidelização destes clientes, especialmente, pelo maior risco na escolha do fornecedor (não dá para avaliar previamente o serviço, diferente de produtos), a necessidade de participação do cliente (escolhas das peças, por exemplo), entre outros aspectos típicos de serviços, mas somente na perspectiva dos clientes. A forte relação entre percepções de qualidade e lealdade do cliente implica que as oficinas autorizadas devem estar interessadas em 
fornecer produtos de maior qualidade para fidelizar seus clientes (DEVARAJ; MATTA; CONLON, 2001).

Concentrar-se nos antecedentes da qualidade do serviço ajudará as oficinas a melhorar a satisfação e a lealdade do cliente. A qualidade do serviço de reparos automotivos é um indicativo de satisfação e lealdade do cliente (IZOGO; OGBA, 2015). Compreender as percepções dos clientes em termos das considerações holísticas, infraestrutura da oficina e empatia no atendimento podem apoiar a tomada de decisões em relação às iniciativas a serem realizadas. (ANDRONIKIDIS, 2009)

Quando o relacionamento entre as percepções dos consumidores e as intenções de recompra é positivo, os consumidores que possuem com carros de alta qualidade de serviços ficam mais satisfeitos com a compra e, portanto, mais propensos a comprar outros serviços no futuro (DEVARAJ; MATTA; CONLON, 2001). Anadronikidis (2009) sugere aos gerentes que personalizem o pacote holístico de serviços oferecidos. Além disso, se a satisfação dos clientes com as diferentes dimensões da qualidade do serviço de reparo de automóveis for muito baixa e nada for feito pelas oficinas para corrigir essas deficiências, seu sucesso a longo prazo pode ser afetado (IZOGO; OGBA, 2015).

Nos estudos realizados por Devaraj, Matta e Conlon (2001), Anadronikidis (2009), Jahanshahi et al. (2011), Izogo e Ogba (2015) e Izogo (2015), os resultados indicaram que a empatia no atendimento ao cliente e a qualidade dos serviços realizados influenciam a satisfação do cliente. Consequentemente aos resultados, existe uma relação positiva entre o atendimento ao cliente e qualidade dos serviços com satisfação, fidelização e lealdade dos clientes no contexto da indústria automotiva.

Para Devaraj, Matta e Conlon (2001), há uma relação positiva entre como os clientes estão satisfeitos com seus carros e quão satisfeitos estão com o atendimento de serviço nas oficinas mecânicas, aumentando o uso de serviços da oficina. Isso implica que, ao fornecer serviços de melhor qualidade, as oficinas mecânicas poderão estabelecer relacionamentos de longo prazo com seus clientes. Manter os altos padrões de serviço é o desafio das oficinas mecânicas.

\section{PROCEDIMENTOS METODOLÓGICOS}

\subsection{CLASSIFICAÇÃO DA PESQUISA}

Revista Eletrônica Gestão e Serviços v.11, n. 2, pp. 3240 - 3260, Julho/Dezembro 2020. ISSN Online: 2177-7284 e-mail: regs@metodista.br 
Esta pesquisa é classificada como quantitativa. $\mathrm{O}$ método quantitativo emprega estratégias de investigação, como experimentos, levantamentos e coleta de dados, instrumentos predeterminados que geram dados estatísticos (CRESWELL, 2010). Quanto aos objetivos, esta pesquisa é classificada como exploratória e descritiva. Em relação aos procedimentos técnicos, a pesquisa é do tipo survey.

Esse tipo de pesquisa exige a interrogação direta, por meio de questionários, com o objetivo de obter informações sobre características, ações ou opiniões de determinados grupos bem como conhecer o comportamento de pessoas (FARIAS FILHO, 2018).

\subsection{INSTRUMENTO DE COLETA DE DADOS}

O questionário utilizado neste estudo foi dividido em três seções. A primeira explica os objetivos desta pesquisa e os entrevistados tiveram que concordar com o Termo de Consentimento Livre e Esclarecido (TCLE) para prosseguir para a segunda e terceira seção. Todos os dados pessoais dos entrevistados foram mantidos em sigilo. A análise dos dados foi realizada de forma agregada e visou estritamente responder aos problemas desta investigação.

A segunda seção é denominada perfil do consumidor automotivo e apresenta questões sobre as características dos entrevistados e sobre os seus automóveis. Por sua vez, a terceira seção é denominada comportamento do consumidor. Esta seção é composta por 33 variáveis que identificam os fatores de influência na decisão de compra dos consumidores. As perguntas são de múltiplas escolhas e afirmativas em escala do tipo Likert, com cinco opções de respostas, sendo 1 para as respostas de menor intensidade, 3 para respostas intermediárias e 5 para respostas de maior intensidade.

O questionário foi aplicado em locais de grande concentração de veículos na cidade de Parauapebas, estado do Pará. Foram aplicados nos estacionamentos de dois supermercados e de um shopping center. O período de aplicação dos questionários foi entre os meses de novembro de 2018 a janeiro de 2019.

\subsection{UNIVERSO E AMOSTRA}

O público alvo são os proprietários de veículos que residam na cidade de 
Parauapebas. A escolha da amostra é por amostragem probabilística aleatória simples, pois é assim denominada quando todos os elementos da população tiveram uma probabilidade ou a chance conhecida e diferente de zero de pertencer à amostra.

A amostra classificada como probabilística aleatória simples, foi calculada com 95\% de margem de segurança e 7,47\% de erro máximo admitido. A pesquisa de campo foi composta por 178 questionários válidos. Para o cálculo da amostra, foi utilizada a Equação 1, conforme Castro et al. (2006):

$n=\left(0,25 * Z^{2}\right) /\left(e^{2}\right)$

Em que: $n=$ tamanho da amostra; $Z=$ desvio-padrão relacionado ao índice de confiança; e=erro amostral admitido.

Em relação a quantidade de questionários para aplicação da análise fatorial exploratória, Hair et al. (2009) recomenda que a amostra deve ser superior a 50 observações e aconselha o mínimo de 100 observações para os resultados serem mais robustos. Outro aspecto mencionado por Hair et al. (2009) é que a razão entre a quantidade da amostra (178) e a quantidade de variáveis (33) deve ser superior a 5, sendo neste trabalho, a razão de 5,39.

\subsection{TRATAMENTO E ANÁLISE DOS RESULTADOS}

Os dados foram tratados com a utilização de estatística descritiva e multivariada. As técnicas de estatística descritivas contribuíram para explicar os resultados das 33 variáveis e incluíram a média, mediana, moda e desvio padrão. Entre as técnicas multivariadas, foi escolhida a análise fatorial exploratória por sua adequação ao objetivo da investigação. A análise fatorial exploratória é uma técnica multivariada, que tem como principal característica sua especial capacidade para sumarizar grande volume de dados em reduzido número de dimensões latentes, denominadas fatores (HAIR et al., 2009).

\section{DISCUSSÃO DOS RESULTADOS}

Revista Eletrônica Gestão e Serviços v.11, n. 2, pp. 3240 - 3260, Julho/Dezembro 2020. ISSN Online: 2177-7284 e-mail: regs@metodista.br 


\subsection{PERFIL DOS ENTREVISTADOS}

A pesquisa contou com a participação de 178 consumidores entrevistados. A média de idade dos entrevistados foi de 34,1 anos, sendo $58 \%$ dos entrevistados do sexo feminino e média de idade de 34,4 anos e $42 \%$ do sexo masculino e média de idade de 33,8 anos. $77,5 \%$ possuem apenas um veículo, 20,2\% dois veículos e 2,3\% três veículos $2,3 \%$. Para aqueles entrevistados com mais de um veículo, foi solicitado que escolhessem o veículo principal e respondessem as questões especificas, como o ano de fabricação, a marca e tempo de uso.

Quanto ao ano de fabricação e a garantia de fábrica, constatou-se que 56,75\% dos automóveis dos entrevistados foram fabricados entre os anos de 2013 a 2018, enquanto 41\% haviam sidos produzidos de 2003 a 2012 e apenas 2,25\% foram fabricados até 2002. Observou-se que os fabricantes costumam oferecer prazos de garantia para alguns componentes dos veículos comprados novos $(0 \mathrm{~km})$ no prazo médio de 3 anos, visto que após esse período existem os desgastes naturais do carro.

Identificou-se no perfil desses consumidores que a decisão pela compra de um automóvel usado é a escolha de 52,8\% dos entrevistados e 47,2\% preferem adquirir veículos novos. No que se refere as marcas adquiridas pelos entrevistados, a Volkswagem é a opção de 31,46\% dos entrevistados, seguida pela General Motors (Chevrolet) com 15,73\%, Ford com 11,80\%, Fiat com 10,67\%, Hyundai com 8,43\%, Honda com 7,30\%, Renault e Toyota com 4,5\%, Mitsubishi com 2,80\%, Chery com $1,69 \%$, Nissan e Pegeout com 0,56 \%.

Com relação ao período que estão usando os veículos, $16,85 \%$ dos entrevistados possuem seu veículo há menos de um ano, 35,95\% dos entrevistados entre 1 a 3 anos e $28,66 \%$ entre 3 a 6 anos. Essa informação está em consonância com o tempo de troca dos veículos, visto que 53,9\% dos entrevistados afirmaram que trocam de veículos a cada 5 anos ou mais e 32\% trocam entre 3 e 4 anos. Apenas 3,4\% dos entrevistados trocam de veículos anualmente e $10,7 \%$ a cada 2 anos.

Os entrevistados responderam sobre onde eles realizam os serviços de reparos automotivos. 41,6\% dos entrevistados informaram realizar serviços apenas em concessionárias autorizadas pelos fabricantes, 52,8\% realizam serviços em oficinas multimarcas e 5,6\% dos pesquisados são indiferentes quanto ao local de realização dos serviços. 
Os resultados indicaram que $70,5 \%$ dos entrevistados que possuem renda entre 1 a 6 salários mínimos contratam os serviços de reparos nas oficinas mecânicas multimarcas, enquanto $63,3 \%$ dos entrevistados com renda acima de 6 salários mínimos contratam serviços de reparos nas redes autorizadas pelos fabricantes. Em relação a realização de pesquisa de preços antes da aquisição de serviços de reparos automotivos, $69,7 \%$ dos entrevistados fazem pesquisa de preços antes de contratarem serviços automotivos.

\subsection{VARIÁVEIS DE INFLUÊNCIA}

Para a identificação da intensidade de influência das 33 variáveis na decisão de compra e comportamento do consumidor, foi realizada uma análise descritiva dos resultados. Os resultados foram organizados na Tabela 1 e as variáveis são apresentadas em ordem descrente da média das respostas.

Considera-se que quanto maior a média, maior a intensidade de concordância dos entrevistados sobre a variável analisada. Para medir a consistência interna do questionário, foi verificado a confiabilidade pelo coeficiente alpha de Cronbach $(0,850)$. O resultado é considerado aceitável. Hair et al. (2009) destacam que alfas superiores a 0,600 em uma escala de 0,000 a 1,000, são considerados satisfatórios.

As variáveis mais influentes para os consumidores foram a confiabilidade na

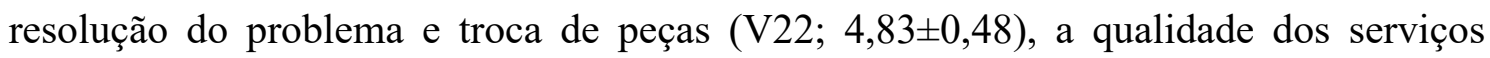
prestados (v12;4,83 $\pm 0,53)$, assertividade no diagnóstico da problemática (v13; $4,83 \pm 0,42)$, preço condizente com o mercado $(23 ; 4,83 \pm 0,44)$ e serviços e peças com garantia (v30; 4,81 $\pm 0,53)$. Esses resultados demonstraram que a qualidade dos serviços prestados pelas empresas é um diferencial para os clientes.

Para Churchill e Peter (2012), as decisões de compra, levam em consideração a percepção do cliente sobre a troca efetuada, pois o que é ofertado pode não valer o preço cobrado, por isso é importante descobrir as percepções de valor sobre uma troca e o preço que o cliente estaria disposto a pagar por ela. Com isso, a pesquisa revela que os clientes buscam segurança, confiança e garantia junto ao prestador dos serviços, desde que o valor cobrado esteja de acordo com os preços praticados no mercado de serviços automotivos.

As variáveis identificadas na pesquisa que envolvem o relacionamento com os 
clientes podem ser usadas como estratégias de marketing e ser facilmente implementadas pelas empresas do ramo automotivo. Os consumidores compreenderam como importante o ambiente da empresa que transmita seriedade (v24; 4,38 $\pm 0,84$ ), relacionamento com o cliente e feedbacks (v33), permitir agendamento de horários

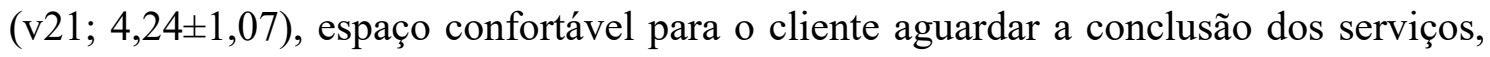
relacionamento estreito com o mecânico $(\mathrm{v} 15 ; 4,19 \pm 1,00)$ e recebimento de notificações

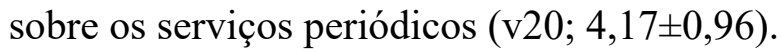

Tabela 1 - Variáveis de influência

\begin{tabular}{|c|c|c|c|c|c|}
\hline & Variáveis & Média & Mediana & Moda & $\begin{array}{l}\text { Desvio } \\
\text { padrão }\end{array}$ \\
\hline $\mathrm{v} 22$ & Confiabilidade na resolução do problema e troca de peças & 4,83 & 5,00 & 5,00 & 0,48 \\
\hline $\mathrm{v} 12$ & Qualidade dos serviços prestados & 4,83 & 5,00 & 5,00 & 0,53 \\
\hline v13 & Assertividade no diagnóstico da problemática & 4,83 & 5,00 & 5,00 & 0,42 \\
\hline v23 & Preço condizente com o mercado & 4,83 & 5,00 & 5,00 & 0,44 \\
\hline v30 & Serviços e peças com garantia & 4,81 & 5,00 & 5,00 & 0,53 \\
\hline v29 & Uso de peças originais ou similares de confiança & 4,70 & 5,00 & 5,00 & 0,59 \\
\hline v19 & Capacitação dos mecânicos diante das inovações tecnológicas & 4,69 & 5,00 & 5,00 & 0,60 \\
\hline v14 & Rapidez na prestação dos serviços & 4,60 & 5,00 & 5,00 & 0,70 \\
\hline v16 & Acompanhamento no local da prestação do serviço & 4,59 & 5,00 & 5,00 & 0,70 \\
\hline v31 & Condições de pagamento facilitadas & 4,57 & 5,00 & 5,00 & 0,79 \\
\hline $\mathrm{v} 27$ & Estrutura física preparada para executar qualquer tipo de serviço & 4,57 & 5,00 & 5,00 & 0,70 \\
\hline v17 & Ambiente da oficina limpo e organizado & 4,40 & 5,00 & 5,00 & 0,81 \\
\hline v24 & Ambiente da empresa que transmita seriedade & 4,38 & 5,00 & 5,00 & 0,84 \\
\hline v33 & Relacionamento com o cliente (feedback) & 4,29 & 5,00 & 5,00 & 1,01 \\
\hline $\mathrm{v} 25$ & Preocupação da oficina perante as questões ambientais & 4,27 & 5,00 & 5,00 & 0,94 \\
\hline $\mathrm{v} 21$ & Permite o agendamento de horário & 4,24 & 5,00 & 5,00 & 1,07 \\
\hline & Faço pesquisa de preço antes das compras & 4,24 & 5,00 & 5,00 & 1,22 \\
\hline v18 & Espaço confortável para o cliente aguardar os serviços & 4,22 & 5,00 & 5,00 & 1,02 \\
\hline $\mathrm{v} 15$ & Relacionamento com o mecânico & 4,19 & 4,00 & 5,00 & 1,00 \\
\hline v20 & Recebimento de notificações sobre os serviços que precisam ser feitos & 4,17 & 4,00 & 5,00 & 0,96 \\
\hline $\mathrm{v} 10$ & Analiso todas as informações antes das compras & 4,07 & 4,00 & 5,00 & 1,17 \\
\hline & Indicação de amigos & 4,03 & 4,00 & 5,00 & 1,11 \\
\hline v26 & Colaboradores uniformizados & 3,88 & 4,00 & 5,00 & 1,12 \\
\hline $\mathrm{v} 32$ & Serviço delivery (buscar e devolver o automóvel) & 3,67 & 4,00 & 5,00 & 1,30 \\
\hline v2 & Propaganda boca a boca & 3,66 & 4,00 & 4,00 & 1,30 \\
\hline v9 & Compro sem analisar as informações apenas quando é urgente & 3,64 & 4,00 & 4,00 & 1,30 \\
\hline v28 & Localização da oficina próxima à residência ou trabalho & 3,62 & 4,00 & 4,00 & 1,17 \\
\hline & Indicação de familiares & 3,43 & 4,00 & 5,00 & 1,52 \\
\hline & Valorizo oficinas ambientalmente corretas & 3,41 & 4,00 & 4,00 & 1,33 \\
\hline & Propagandas em meios de comunicação & 3,18 & 3,00 & 3,00 & 1,21 \\
\hline v6 & Gasto sem pesquisar preço apenas quando é urgente & 2,97 & 3,00 & 4,00 & 1,37 \\
\hline & Valorizo o status que minhas decisões de compra me proporcionam & 2,89 & 3,00 & 1,00 & 1,51 \\
\hline
\end{tabular}




\section{Fonte: Dados da pesquisa.}

As empresas têm usado informações sobre os clientes para executar o marketing de precisão concebido para construir sólidos relacionamentos a longo prazo (KOTLER; KELLER, 2012). A gestão do relacionamento com os clientes dos serviços de reparos automotivos permite aprimorar o atendimento e visa atender as necessidades dos clientes (DEVARAJ; MATTA; CONLON, 2001; ANDRONIKIDIS, 2009; JAHANSHAHI, 2011).

O uso cuidadoso e detalhado das informações obtidas sobre cada cliente, em qualquer ocasião que ele venha a ter contato com a organização, esse tipo de gerenciamento permite maximizar a fidelidade, impulsionar a lucratividade, a competitividade da empresa e agregar valor à base de clientes.

Diante dos resultados, é evidente a percepção do cliente quanto à importância do uso de ferramentas de relacionamento entre empresa e cliente, e como o uso da gestão de relacionamento com o cliente pode beneficiar ambos os lados. Por outro lado, as variáveis menos influentes para os consumidores foram: o gasto sem pesquisar preço apenas quando é urgente (v6; 2,97 $\pm 1,37$ ), valorizo o status que minhas decisões de

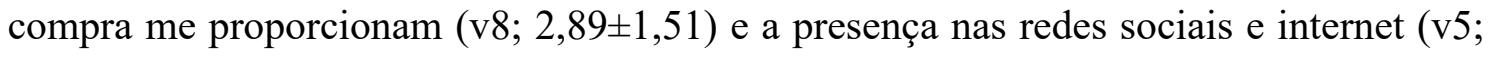
$2,84 \pm 1,24)$. Os consumidores de serviços de reparos automotivos demonstraram que o preço dos serviços é uma variável importante para a tomada de decisão.

Os consumidores consideram que a escolha da oficina para reparos automotivos e este tipo de compra não dependem de aspectos relacionados ao status social proporcionados pela compra. Na aquisição de um automóvel, o status social é relevante, como exemplifica Rani (2014) ao dizer que um consumidor pode comprar um automóvel da marca Ferrari ou da marca Porsche pela qualidade do carro, mas também por causa dos sinais externos de sucesso social que este tipo de carros representa.

Kotler e Keller (2012) afirmam que os consumidores de serviços costumam confiar mais nas informações boca a boca do que em propagandas na mídia. Os resultados demostraram que a influência pela escolha do local de contratação dos serviços automotivos ocorre principalmente por meio de indicação de amigos (v3; $4,03 \pm 1,11$ ) e que a presença nas redes sociais e a internet (v5; $2,84 \pm 1,24$ ) são os que têm menos influência.

Segundo Solomon (2016), um grupo de referência é formado por indivíduos, 
reais ou imaginários, que são capazes de ter importância significativa nas avaliações, aspirações ou comportamento de uma pessoa. Observa-se que os grupos de referência têm importância significativa como influenciadores na seleção do local de contratação

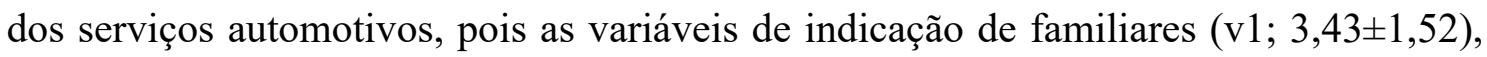
propaganda boca a boca (v2; 3,66 $\pm 1,30)$ e indicação de amigos (v3; 4,03 $\pm 1,11)$ tiveram resultados expressivos nas médias.

\subsection{ANÁLISE FATORIAL DOS RESULTADOS}

A Matriz Anti-Imagem e as Comunalidades $\left(h^{2}\right)$ foram usadas como critérios para a manutenção das variáveis no modelo. Os resultados dos testes de Kaiser-MeyerOlkin $(0,823)$ e de esfericidade de Bartlett $(\chi 2=866,293$ e sig.<0,000) confirmaram a utilização da técnica satisfatoriamente, conforme Hair et al. (2009). Esses resultados possibilitaram o prosseguimento do tratamento de dados e a utilização da análise fatorial exploratória (AFE) para sumarizar as variáveis e identificar os fatores latentes.

A Tabela 2 apresenta os resultados da carga fatorial e comunalidades para as variáveis explicadas.

Tabela 2 - Matriz de Cargas Fatoriais ( $\alpha$ ) e Comunalidades $\left(h^{2}\right)$

\begin{tabular}{|c|c|c|c|c|}
\hline \multirow{2}{*}{ Variáveis } & \multicolumn{3}{|c|}{ Componente (Fator) } & \multirow{2}{*}{$\mathbf{h}^{2}$} \\
\hline & 1 & 2 & 3 & \\
\hline v25 Preocupação da oficina perante as questões ambientais & 0,816 & 0,102 & 0,074 & 0,683 \\
\hline v18 Espaço confortável para o cliente aguardar os serviços & 0,813 & 0,147 & 0,228 & 0,734 \\
\hline v26 Colaboradores uniformizados & 0,783 & $-0,097$ & 0,030 & 0,623 \\
\hline v17 Ambiente da oficina limpo e organizado & 0,775 & 0,224 & 0,222 & 0,700 \\
\hline v24 Ambiente da empresa que transmita seriedade & 0,697 & 0,251 & 0,181 & 0,582 \\
\hline v13 Assertividade no diagnóstico da problemática & $-0,022$ & 0,837 & 0,058 & 0,704 \\
\hline v23 Preço condizente com o mercado & 0,311 & 0,730 & $-0,007$ & 0,630 \\
\hline v22 Confiabilidade na resolução do problema e troca de peças & 0,210 & 0,685 & 0,414 & 0,685 \\
\hline v12 Qualidade dos serviços prestados & 0,028 & 0,578 & 0,533 & 0,619 \\
\hline v30 Serviços e peças com garantia & 0,151 & 0,227 & 0,890 & 0,866 \\
\hline v29 Uso de peças originais ou similares de confiança & 0,274 & 0,005 & 0,832 & 0,768 \\
\hline
\end{tabular}

Fonte: Dados da pesquisa.

Dessa forma, a extração dos fatores ocorreu pelo critério do Autovalor, extraído com a técnica de Componentes Principais e rotação ortogonal pelo método Varimax. Esse conjunto de procedimentos possibilitou reduzir as 33 variáveis originais em 12, organizadas em três fatores denominados como: (1) imagem da oficina, (2) confiança na oficina e (3) serviços e peças. 
Juntas, estas dimensões explicaram 69,047\% da variância da nuvem de dados (Tabela 3). Cada fator analisado revela estruturas latentes, mas que não são observáveis pela leitura direta das variáveis quando observadas separadamente. Todas as variáveis apresentaram comunalidade acima de 0,500. Esses resultados mostram que pelo menos $50 \%$ da variância das variáveis foram explicadas pelos fatores.

A consistência interna dos fatores foi avaliada pelo coeficiente Alpha de Cronbach. Mensurar a consistência interna é uma etapa necessária para avaliar os fatores e o questionário. $\mathrm{O}$ intuito é saber se eles demostram capacidade de medir o que se propõem a fazê-lo.

Tabela 3 - Resultado da Análise Fatorial

\begin{tabular}{llcccc}
\hline Denominação do Fator & $\begin{array}{c}\text { Alpha de } \\
\text { Cronbach }\end{array}$ & $\begin{array}{c}\text { Quantidade de } \\
\text { Variáveis }\end{array}$ & Autovalor & Variância Explicada \\
\hline Fator 1 & Imagem da oficina & 0,857 & 5 & 3,268 & $29,71 \%$ \\
Fator 2 & Confiança na oficina & 0,763 & 4 & 2,243 & $20,39 \%$ \\
Fator 3 & Serviços e peças & 0,808 & 2 & 2,084 & $18,95 \%$ \\
\hline \multicolumn{2}{c}{ Total } & 0,889 & 11 & 7,595 & $69,05 \%$ \\
\hline
\end{tabular}

Fonte: Dados da pesquisa.

A primeira dimensão, ou fator, encontrada representou $29,71 \%$ da variância dos dados e agregou as variáveis relacionadas à imagem da oficina. As questões relacionadas à organização, limpeza e aspectos ambientais foram consideradas influentes para os consumidores. As oficinas geram resíduos que podem provocar danos ao meio ambiente se não forem descartados corretamente. A organização e limpeza dos espaços passa aos clientes uma melhor imagem da oficina (IZOGO; OGBA, 2015).

Outras características da imagem da oficina estão relacionadas a organização do local. Os consumidores preferem oficinas que possuam uma sala de espera confortável. Investir em uma sala de espera representa um atrativo para os clientes contratarem serviços das oficinas (TAN; YU; YIN, 2009, IZOGO, 2015). Colaboradores uniformizados e uma empresa que demonstre seriedade foram características relevantes neste fator de influência. Definitivamente, a imagem da oficina é um fator de influência para a decisão de compra (DEVARAJ; MATTA; CONLON, 2001; JAHANSHAHI, 2011; IZOGO, 2015; IZOGO; OGBA, 2015).

A segunda dimensão foi responsável por explicar $20,39 \%$ da variabilidade dos dados e agregou as variáveis de confiança na oficina. Os clientes querem que os seus problemas sejam resolvidos com assertividade. A qualidade do atendimento é uma 
característica importante deste fator de influência. Os preços cobrados pelas oficinas devem ser justos e condizentes com a qualidade exigida (JAHANSHAHI, 2011). A confiança na oficina é a combinação de alta qualidade, assertividade nos diagnósticos e preços justos (ANDRONIKIDIS, 2009; JAHANSHAHI, 2011).

A terceira dimensão encontrada explicou $18,95 \%$ da variabilidade dos dados e agregou as variáveis relacionadas aos serviços e peças. Os carros são bem preciosos para muitos consumidores. A exigência dos clientes é que as peças e os serviços possuam garantias de qualidade. Em caso de problemas recorrentes, a oficina faça os devidos consertos e reposições de peças dentro das garantias estabelecidas (ANDRONIKIDIS, 2009; JAHANSHAHI, 2011; IZOGO, 2015). As garantias das peças e serviços prestados pelas oficinas são fatores que influenciam a decisão de compra dos consumidores.

\section{CONCLUSÃO}

O comportamento do consumidor tem interferência de fatores culturais, pessoais, sociais e psicológicos, que estão constantemente influenciando a decisão de compra das pessoas. Compreender o comportamento do consumidor de serviços automotivos é importante para que os administradores possam elaborar estratégias para atender as expectativas de seus consumidores.

Observou-se que três fatores influenciam a decisão de compra dos consumidores de serviços de reparos automotivos. O primeiro está relacionado à imagem da oficina. Os consumidores preferem oficinas que tenham um ambiente organizado e limpo, com espaço confortável para aguardar a finalização dos serviços, com colaboradores uniformizados e que esteja preocupada com questões relacionadas ao meio ambiente, como descarte adequado dos resíduos gerados pela oficina.

O segundo fator de influência é a confiança na oficina. A alta qualidade na prestação dos serviços e preços condizentes com o mercado são aspectos relevantes para criar confiança na relação entre clientes e oficina. Para os clientes confiarem nas oficinas é necessário assertividade nos diagnósticos e solução nos problemas dos veículos. O preço cobrado deve ser justo com as expectativas do cliente.

O terceiro fator de influência são peças e serviços com garantias. As oficinas devem fornecer peças e serviços com garantia de uso e troca. Os clientes preferem as oficinas que oferecem garantias dos serviços, dessa maneira, demonstram que estão 
preocupadas em atender efetivamente as necessidades e expectativas dos clientes.

A recomendação deste trabalho é que as oficinas analisem as características do comportamento dos consumidores e os fatores que influenciam à decisão de compra. As oficinas devem priorizar o atendimento de alta qualidade e investir em infraestrutura para proporcionar conforto e comodidade aos clientes.

Este trabalho possui pelo menos duas limitações. A primeira é a uma abordagem unidimensional, apenas obtendo uma percepção do cliente para as três dimensões encontradas. É possível que as oficinas mecânicas tenham limitações de custo e alta concorrência para implantar melhorias na qualidade dos serviços. Outra limitação deste trabalho é a relação custo e qualidade. É possível que os clientes desejem os melhores serviços possíveis a um custo relativamente inferior, desta maneira, encontrar a razão ideal entre custo e qualidade pode ter elevada complexidade na relação entre clientes e oficinas.

Sugere-se novas pesquisas para verificar a medição de desempenho dos serviços automotivos e sua relação com a satisfação e fidelização dos clientes. Entender como é possível desenvolver a gestão de desempenho na relação entre qualidade, satisfação e fidelização pode ampliar os horizontes deste tema de pesquisa.

Por fim, conclui-se que as oficinas devem implementar ações para atender as necessidades e expectativas dos consumidores, visando obter a preferência na escolha na decisão de compra dos clientes, entretanto, as ações devem ser implantadas com devida cautela para que os resultados sejam positivos também economicamente para a oficina.

\section{REFERÊNCIAS}

ANDRONIKIDIS, A. Linking dimensions of perceived service quality to actual purchase behaviour. EuroMed Journal of Business, v. 4, n. 1, p. 4-20., 2009.

BARROS, D. C.; CASTRO, B. H. R. D.; VAZ., L. F. H. Panorama da indústria de autopeças no Brasil: características, conjuntura, tendências tecnológicas e possibilidades de atuação do BNDES em 2015, 2018. Disponivel em:

$<$ https://web.bndes.gov.br/bib/jspui/handle/1408/9555> . Acesso em: 21 janeiro 2019.

CASOTTI, B. P.; GOLDENSTEIN, M. Panorama do setor automotivo: as mudanças estruturais da indústria e as perspectivas para o Brasil. Portal do BNDES, 2008.

Disponivel em: < https://web.bndes.gov.br/bib/jspui/handle/1408/2566>. Acesso em: 21 janeiro 2019.

CASTRO, G. C. D. et al. Comportamento do consumidor e pesquisa de mercado. São Paulo: FGV, 2006. 
CHISNALL, P. M. Consumer behaviour. [S.1.]: McGraw-Hill, 1995.

CHURCHILL, G. A.; PETER, J. P. Marketing: criando valor para os clientes. $3^{\mathrm{a}}$. ed. São Paulo: Saraiva, 2012.

COBRA, M. Administração de Marketing no Brasil. 4a . ed. Rio de Janeiro: Elsevier, 2015.

CRESWELL, J. W. Projeto de pesquisa: métodos qualitativo, quantitativo e misto. $3^{\mathrm{a}}$. ed. Porto Alegre: Artmed/Bookman., 2010.

DEVARAJ, S.; MATTA, K. F.; CONLON, E. Product and service quality: the antecedents of customer loyalty in the automotive industry. Production and Operations Management, v. 10, n. 4, p. 424-439, 2001.

FARIAS FILHO, M. C. Elaboração de artigos cientificos para publicação: Um guia para ciências sociais, sociais aplicadas e humanidades. [S.1.]: Motres, v. 1, 2018.

GIL, A. C. Métodos e técnicas de pesquisa social. 6a . ed. São Paulo: Atlas, 2008.

HAIR, J. F. et al. Análise multivariada de dados. $6^{\mathrm{a}}$. ed. Porto Alegre: Bookman, 2009.

IZOGO, E. E. Customers' service quality perception in automotive repair. African

Journal of Economic and Management Studies, v. 6, n. 3, p. 272-288, 2015.

IZOGO, E. E.; OGBA, I.-E. Service quality, customer satisfaction and loyalty in automobile repair services sector. International Journal of Quality \& Reliability Management, v. 32, n. 3, p. 250-269, 2015.

JAHANSHAHI, A. A. E. A. Study the effects of customer service and product quality on customer satisfaction and loyalty. International Journal of Humanities and Social Science, v. 1, n. 7, p. 253-260, 2011.

KOROCOSKI, S. R.; FERREIRA, P. L.; ATAMANCZUK, M. J. A Qualidade Percebida por Consumidores de Serviços de Reparação Automotiva: uma aplicação do Modelo Servqual. Revista Organizações em Contexto, v. 12, n. 23, p. 221-240, 2016.

KOTLER, P.; KELLER, K. L. Administração de marketing. $14^{\mathrm{a}}$. ed. São Paulo: Pearson Education, 2012.

LARENTIS, F. Comportamento do Consumidor. Curitiba: Iesde, 2012.

LIMEIRA, T. M. V. Comportamento do consumidor brasileiro. São Paulo: Saraiva, 2008.

MEDEIROS, J. F. D.; CRUZ, C. M. L. Comportamento do Consumidor: Fatores que influenciam no processo de decisão de compra dos consumidores. Revista Teoria e evidência econômica, v. 14, p. 167-190, 2006.

OLIVEIRA, P. et al. O papel de atributos da qualidade de serviços e da satisfação na lealdade de clientes de um centro automotivo. Revista Eletrônica Gestão e Serviços, v. 5, n. 1, p. 849-868, 2014.

PANDO, A. A.; PANDO, C. A. Comportamento do consumidor e o processo de decisão de compra. Revista Teste, v. 2, n. 2, p. 21-30, 2013.

PRODANOV, C. C.; FREITAS, E. C. D. Metodologia do trabalho científico: métodos e técnicas da pesquisa e do trabalho acadêmico. $2^{\mathrm{a}}$. ed. Novo Hamburgo: Feevale, 2013.

Revista Eletrônica Gestão e Serviços v.11, n. 2, pp. 3240 - 3260, Julho/Dezembro 2020. ISSN Online: 2177-7284 e-mail: regs@metodista.br 
RANI, P. Factors influencing consumer behaviour. International journal of current research and academic review, v. 2, n. 9, p. 52-61, 2014.

SANEMATSU, L. S. A.; SILVA, A. R.; VIEIRA, A. M. Relação entre fabricante e varejista: um estudo qualitativo comparativo no setor de peças automotivas. NAVUS Revista de Gestão e Tecnologia, v. 6, n. 3, p. 56-69, 2016.

SETH, J.; MITTAL, B.; NEWMAN, B. Comportamento do cliente: indo além do comportamento de do consumidor. São Paulo: Atlas, 2001.

SINDICATO NACIONAL DA INDÚSTRIA DE COMPONENTES PARA VEÍCULOS [SINDIPEÇAS]. Relatório de Frota Circulante 2018, 2018. Disponivel em:

$<$ https://www.sindipecas.org.br/sindinews/Economia/2018/R_Frota_Circulante_2018.p df. $>$. Acesso em: 12 novembro 2018.

SOLOMON, M. R. Comportamento do consumidor: Comprando, possuindo e sendo. $11^{\mathrm{a}}$. ed. São Paulo: Bookman, 2016.

TAN, H.; YU, K.; YIN, Z. Study on the service station on performance evaluation for the automotive aftermarket repair and maintenance. International Conference on Information Management, Innovation Management and Industrial Engineering, v. 3, p. 336-339, 2009. 